\title{
CONTROLE DA MATURAÇÃO DE CAQUI 'FUYU' COM APLICAÇÃO DE AMINOETOXIVINILGLICINA E 1-METILCICLOPROPENO ${ }^{1}$
}

\author{
AURI BRACKMANN ${ }^{2}$, MÁRCIO RENAN WEBER SCHORR ${ }^{3}$, ADRIANO ROQUE DE GASPERIN ${ }^{4}$, \\ THIAGO LIBERALESSO VENTURINI ${ }^{5}$, JOSUEL ALFREDO VILELA PINTO ${ }^{6}$
}

RESUMO - O armazenamento de caquis é uma ferramenta importante na manutenção da qualidade e no prolongamento da oferta do fruto após a colheita. O objetivo deste trabalho foi avaliar o efeito da aplicação de AVG em pré-colheita, e do 1-MCP, em pré e pós-armazenamento, sobre a manutenção da qualidade póscolheita e seu efeito na incidência de distúrbios em caquis 'Fuyu' armazenados em atmosfera controlada a $-0,5^{\circ} \mathrm{C}$ e transferidos a condição de ambiente $\left(20^{\circ} \mathrm{C}\right)$ por 6 dias. Os tratamentos foram: [1] controle; [2] aplicação de AVG (123 $\left.\mathrm{g} \mathrm{ha}^{-1}\right)$; [3] aplicação de 1-MCP $\left(1,0 \mu \mathrm{L} \mathrm{L}^{-1}\right)$ em pré-armazenamento; [4] aplicação de AVG e 1-MCP em pré-armazenamento; [5] aplicação de 1-MCP em pós-armazenamento; [6] aplicação de AVG e 1-MCP em pós-armazenamento. Os frutos foram avaliados quanto à qualidade na ocasião da colheita, visando à caracterização do lote e, após quatro meses de armazenamento a $-0,5^{\circ} \mathrm{C}$ e mais seis dias a $20^{\circ} \mathrm{C}$, quanto à firmeza da polpa, $\mathrm{pH}$, coloração da casca, índices de amaciamento e de escurecimento, teores de sólidos solúveis e de acidez titulável, respiração, produção de etileno, além da atividade da enzima ACC oxidase. Os resultados indicaram que a aplicação de 1-MCP em pré ou em pós-armazenamento foi eficiente em conter o amaciamento da polpa de caquis 'Fuyu' previamente armazenados em atmosfera controlada a $-0,5^{\circ} \mathrm{C}$ e mantidos a $20^{\circ} \mathrm{C}$ por seis dias. Todavia, o uso deste fitorregulador em pré-armazenamento ocasionou maior escurecimento da epiderme. O uso de AVG em pré-colheita não retardou a maturação de caquis 'Fuyu' armazenados na mesma condição.

Termos para indexação: Diospyrus kaki, atmosfera controlada, amaciamento.

\section{MATURATION CONTROL OF PERSIMMONS cv. 'FUYU' WITH AMINOETHOXYVINYLGLICINE AND 1 METHYLCYCLOPROPENE APLICATION}

\begin{abstract}
The storage of persimmons is an important tool to maintain the quality and to extend the fruit offer after harvest. The aim of this study was to evaluate the effect of preharvest application of aminoethoxyvinylglycine (AVG) and 1-methylcyclopropene (1-MCP) application before or after storage on the ripening control of persimmons cv. Fuyu during storage in controlled atmosphere (CA) at $-0.5{ }^{\circ} \mathrm{C}$ during 4 months. The treatments were: [1] control; [2] AVG (123 $\left.\mathrm{g} \mathrm{ha}^{-1}\right)$ application and CA storage; [3] AVG application and 1-MCP (1.0 $\left.\mu \mathrm{L} \mathrm{L}^{-1}\right)$ application after CA storage; [4] 1-MCP application before CA storage; [5] AVG application and 1-MCP application before CA storage; [6] 1-MCP application after CA storage. According to the results, the 1-MCP maintained higher fruit firmness after storage and during six days at $20^{\circ} \mathrm{C}$. Highest firmness was obtained after six days at $20^{\circ} \mathrm{C}$ with application of 1-MCP after storage. The preharvest application of AVG is not efficient in maturation control of 'Fuyu' persimmons stored during four months in controlled atmosphere.
\end{abstract}

Index terms: Diospyrus kaki, controlled atmosphere, softening.

\footnotetext{
1(Trabalho 195-12). Recebido em: 18-06-2012. Aceito para publicação em: 20-11-2013.

${ }^{2}$ Eng $^{\text {o }}$ Agrônomo, Dr., Professor do Departamento de Fitotecnia da Universidade Federal de Santa Maria (UFSM), Santa Maria - RS. E-mail: auribrackmann@gmail.com.

${ }^{3}$ Eng $^{\circ}$ Agrônomo, Doutorando do Programa de Pós-Graduação em Agronomia, UFSM. E-mail: marcioschorr@hotmail.com.

${ }^{4} E^{2}{ }^{0}$ Agrônomo, EMATER - RS. E-mail: adrianogasperin@gmail.com

${ }^{5}$ Eng $^{\circ}$ Agrônomo, Agropecuária Schio Ltda.,Vacaria - RS. E-mail: thiago311@msn.com

${ }^{6}$ Eng $^{\circ}$ Agrônomo, Dr., Professor da Universidade Federal da Fronteira Sul, Laranjeiras do Sul - PR. E-mail: josuel_vilela@hotmail. com
} 


\section{INTRODUÇÃO}

A produção brasileira de caqui (Diospyrus kaki L.) tem crescido nos últimos anos, tendo em vista os elevados rendimentos que a cultura proporciona, com a área plantada superior a 8.000 hectares (IBGE, 2012). Uma das principais cultivares de caquizeiro produzida é a Fuyu, que apresenta características como frutos sem sementes, polpa branco-amarelada, sabor adocicado, sem adstringência, com baixa acidez e epiderme amarelo-avermelhada.

Apesar dos aumentos tanto na oferta quanto na demanda de caquis no mercado, nos últimos anos, uma maior expansão na produção não tem ocorrido devido aos problemas ocasionados pela falta de tecnologias capazes de manter a oferta do produto por um longo período. A concentração da colheita em um curto período de tempo, associada ao uso de uma única cultivar e à incidência de distúrbios fisiológicos em pós-colheita são alguns dos principais entraves na expansão desta cultura.

O caqui, apesar de ser um fruto climatérico, apresenta baixa taxa de produção de etileno, porém é altamente sensível a este, mesmo quando em baixas concentrações. A ação deste fitormônio induz o amaciamento da polpa, que é indesejável quando se pretende armazenar caquis por longos períodos, e está associado ao desenvolvimento de distúrbios, cujos sintomas são caracterizados pelo rápido e severo amaciamento da polpa, ausência de desenvolvimento da cor e sabor típicos da cultivar, aparência gelatinosa e perda da suculência, podendo em casos mais severos, levar à ausência de suculência (polpa geleificada). Este distúrbio é responsável por gerar grandes perdas e tem comprometido a expansão da cultura (PINTO, 2009).

A aminoetoxivinilglicina (AVG) e o 1-metilciclopropeno (1-MCP) são compostos químicos utilizados no controle da síntese e da ação do etileno, respectivamente. O primeiro inibe a atividade enzimática responsável pela conversão de S-adenosil metionina (SAM) a ácido 1-aminociclopropano-1-carboxílico (ACC), último intermediário na rota de síntese de etileno (YANG; HOFFMANN, 1984). Já o 1-MCP, ligase irreversivelmente ao receptor do etileno na membrana celular, inibindo seu estímulo fisiológico e transdução de sinal (SISLER, 1991). Segundo Ferri et al. (2002), aplicações de AVG em pré-colheita retardaram em 6 dias a maturação de frutos de caqui 'Fuyu' armazenados em condição ambiente $\left(23 \pm 3^{\circ} \mathrm{C}\right.$; $75 \pm 5 \%$ UR), quando comparados à testemunha, além de terem inibido a síntese de etileno.

$\mathrm{O}$ armazenamento de caquis em baixa temperatura reduz a rápida perda de qualidade dos frutos, sendo recomendadas temperaturas abaixo de $5{ }^{\circ} \mathrm{C}$ (COLLINS; TISDELL, 1995). Porém, a exposição a baixas temperaturas ocasiona a rápida perda de firmeza dos frutos, normalmente após sua transferência para a temperatura ambiente. Salvador et al. (2004) verificaram que a aplicação de 1-MCP foi eficiente no controle de danos pelo frio em caquis 'Rojo Brillante', possibilitando maior tempo de armazenamento em baixas temperaturas. Enquanto Luo (2007) relatou que a aplicação do mesmo produto em caquis 'Qiandaowuhe' retardou a atividade das enzimas poligalacturonase e pectinametilesterase, responsáveis pela degradação da parede celular. Além disso, a dose de $3 \mu \mathrm{L} \mathrm{L}^{-1}$ promoveu um aumento na vida de prateleira, de 8 para 22 dias.

A utilização de AVG e 1-MCP são alternativas que podem aumentar o período de armazenamento e, com isso, o período de oferta do caqui. No entanto, há carência na literatura sobre o efeito do uso associado de AVG, aplicado em pré-colheita, e de 1-MCP em pós-colheita, no controle da maturação e na manutenção da qualidade de caquis 'Fuyu'.

Assim, o objetivo deste trabalho foi avaliar o efeito da aplicação de AVG em pré-colheita, e do 1-MCP, em pré e pós-armazenamento, sobre a manutenção da qualidade pós-colheita e seu efeito na incidência de distúrbios em caquis 'Fuyu' armazenados em atmosfera controlada a $-0,5{ }^{\circ} \mathrm{C}$ e transferidos à condição de ambiente.

\section{MATERIAL E MÉTODOS}

O experimento foi conduzido em duas etapas: a primeira, constou da aplicação de AVG em pré-colheita, e a segunda, do armazenamento dos frutos e aplicação do restante dos tratamentos. Foram utilizados frutos de caqui 'Fuyu', produzidos em pomar comercial, localizado no município de Cotiporã - RS, na safra de 2008/2009.

Após a colheita, os frutos foram transportados para o Núcleo de Pesquisa em Pós-Colheita (NPP) do Departamento de Fitotecnia da Universidade Federal de Santa Maria (UFSM), onde foram armazenados. Antes do armazenamento, os caquis foram selecionados, sendo excluídos os frutos com lesões mecânicas, com danos por fungos e insetos, além daqueles de tamanho irregular.

Amostras de 20 frutos foram acondicionadas em minicâmaras experimentais herméticas em Atmosfera controlada (AC), de $0,233 \mathrm{~m}^{3}$, com $1,0 \mathrm{kPa}$ de $\mathrm{O}_{2}$ e $5,0 \mathrm{kPa}$ de $\mathrm{CO}_{2}$, as quais foram dispostas no interior da câmara fria a $-0,5{ }^{\circ} \mathrm{C}$, sendo os caquis mantidos nesta condição por quatro 
meses e, em seguida, a $20{ }^{\circ} \mathrm{C}$ por seis dias. Os tratamentos aplicados resultaram da combinação da aplicação, ou não, de AVG em pré-colheita e de 1-MCP em pré e pós-armazenamento, ou seja: [1] controle; [2] aplicação de AVG em pré-colheita; [3] aplicação de 1-MCP em pré-armazenamento; [4] aplicação de AVG em pré-colheita e 1-MCP em pré-armazenamento; [5] aplicação de 1-MCP em pós-armazenamento; [6] aplicação de AVG em précolheita e 1-MCP em pós-armazenamento.

A aplicação de AVG, produto comercial ReTain $^{\circledR}$ (15\% de ingrediente ativo), foi realizada 20 dias antes da colheita. Foram utilizados a dose de $123 \mathrm{~g} \mathrm{ha}^{-1}$ de ingrediente ativo e volume de calda de $500 \mathrm{~L} \mathrm{ha}^{-1}$, aplicados com pulverizador costal, com capacidade para 20 litros.

A aplicação de 1-MCP foi realizada antes ou após o armazenamento, dependendo do tratamento, sendo para tanto utilizado o produto SmartFresh ${ }^{\circledR}$ (Rohm \& Hass Co), na formulação pó molhável, contendo $0,14 \%$ do ingrediente ativo. Os frutos, dispostos nas minicâmaras $\left(0,233 \mathrm{~m}^{3}\right)$ foram expostos ao produto por 24 horas à temperatura de $-0,5^{\circ} \mathrm{C}$. Para produzir a concentração de $1,0 \mu \mathrm{L} \mathrm{L}^{-1}$ de 1-MCP no interior das minicâmaras, quantidade pré-determinada do SmartFresh ${ }^{\circledR}$, na forma de pó, foi colocada em frascos com tampa. Adicionou-se água destilada e deionizada e agitou-se o frasco até a completa dissolução do produto. Os frascos foram abertos no interior das câmaras, as quais foram fechadas imediatamente para evitar a perda do gás. Após os tratamentos, procedeu-se a exaustão das minicâmaras com auxílio de uma bomba de sucção.

A instalação da atmosfera controlada foi realizada pela varredura do $\mathrm{O}_{2}$ do interior da câmara com gás inerte $\left(\mathrm{N}_{2}\right)$ e posterior injeção de $\mathrm{CO}_{2}$, até as condições desejadas. Realizou-se monitoramento diário das concentrações de $\mathrm{O}_{2}$ e $\mathrm{CO}_{2}$ com o auxílio de um analisador automático de gases marca Kronenberger/Climasul. Com a respiração dos frutos houve consumo do $\mathrm{O}_{2}$, corrigido pela injeção de ar atmosférico, e acúmulo de $\mathrm{CO}_{2}$, eliminado pela absorção com hidróxido de potássio $(\mathrm{KOH})(40 \%)$.

$\mathrm{O}$ delineamento experimental adotado foi o inteiramente casualizado, com 6 tratamentos e 4 repetições de 20 frutos. Cada tratamento foi constituído de 80 caquis, totalizando 480 frutos.

$\mathrm{Na}$ ocasião da colheita os frutos foram caracterizados quanto à firmeza da polpa, $\mathrm{pH}$, respiração, produção de etileno e teores de sólidos solúveis e de acidez titulável. Após quatro meses de armazenamento a $-0,5{ }^{\circ} \mathrm{C}$ e mais seis dias a 20 ${ }^{\circ} \mathrm{C}$, os caquis foram avaliados quanto aos seguintes parâmetros: a) pH: medido diretamente no suco dos frutos, com potenciômetro digital;

b) Acidez titulável (AT): determinada pela titulação de $10 \mathrm{~mL}$ de suco diluídos em $100 \mathrm{~mL}$ de água destilada e deionizada, com $\mathrm{NaOH} 0,1 \mathrm{~N}$ até atingir $\mathrm{pH} 8,1$. Os resultados foram expressos em meq $100 \mathrm{~mL}^{-1}$;

c) Sólidos solúveis (SS): foi quantificado no suco dos frutos, por leitura direta em refratômetro, cujos resultados foram expressos em ${ }^{\circ} \mathrm{Brix}$;

d) Firmeza de polpa: foi medida usandose penetrômetro provido de ponteira de $7,5 \mathrm{~mm}$, aplicado em lados opostos, na região equatorial do fruto, onde previamente se retirou a epiderme. Os resultados foram expressos em Newton $(\mathrm{N})$;

e) Atividade da enzima 1-aminociclopropano-1-carboxílico (ACC) oxidase: determinada através da produção de etileno por aproximadamente $3 \mathrm{~g}$ de epiderme incubados durante 30 minutos em solução contendo $0,1 \mathrm{mM}$ de ACC (ácido 1-aminociclopropano-1-carboxílico) diluído em $10 \mathrm{mM}$ do tampão MES (ácido 2-(N-morfolino) etanossulfônico) em pH 6,0, e posterior adição de $2 \%$ de $\mathrm{CO}_{2}$ e nova incubação por 30 minutos. Em seguida, foram coletadas amostras da composição gasosa dos frascos com o auxílio de uma seringa, as quais foram injetadas em cromatógrafo a gás. Os resultados foram expressos em $\mathrm{nLC}_{2} \mathrm{H}_{4} \mathrm{~g}^{-1} \mathrm{~h}^{-1}$;

f) Cor da epiderme: determinada com o auxílio de colorímetro Minolta ${ }^{\circledR}$, tomando-se leituras da região mediana da casca. Os resultados foram expressos em luminosidade (L), ângulo de cor (Hue) e cromaticidade $(\mathrm{C})$;

g) Índice de amaciamento: avaliado subjetivamente atribuindo-se notas, em que: $0=$ sem ocorrência de amaciamento; 1 = início e menos que $10 \%$ do fruto amaciado; $2=$ de 10 a $50 \%$ do fruto amaciado; $3=>50$ a $100 \%$ do fruto amaciado, sendo o índice obtido pela soma dos produtos do número de frutos pelo respectivo nível, dividido pelo número total de frutos da amostra;

h) Índice de escurecimento: foi determinado subjetivamente pela observação da ocorrência de escurecimento da polpa, atribuindo-se notas, em que: $0=$ sem presença de escurecimento da epiderme; $1=$ até $10 \%$ da epiderme escurecida; $2=>10$ a $20 \%$ da epiderme escurecida; $3=>20 \%$ a $30 \%$ da epiderme escurecida; e $4=>30 \%$ da epiderme escurecida, sendo o índice obtido pela soma dos produtos do número de frutos pelo seu respectivo nível de escurecimento, dividido pelo número total de frutos da amostra; 
i) Produção de etileno: determinada com auxílio de cromatógrafo gasoso (marca Varian, detector de ionização por chama (FID) e coluna Porapak N80/100, temperatura da coluna $=90{ }^{\circ} \mathrm{C}$, injetor $=140{ }^{\circ} \mathrm{C}$ e detector $=200^{\circ} \mathrm{C}$ ), em função da massa de frutos e do período de acumulação do gás em recipiente hermeticamente fechado, expressa em $\mu \mathrm{LC}_{2} \mathrm{H}_{4} \mathrm{~kg}^{-1} \mathrm{~h}^{-1}$;

j) Taxa respiratória: determinada por analisador eletrônico de gases (Agri-datalog ${ }^{\circledR}$ ), em função da massa de frutos e do tempo de acumulação de $\mathrm{CO}_{2}$ em recipiente hermeticamente fechado, expressa em $\mathrm{mLCO}{ }_{2} \mathrm{~kg}^{-1} \mathrm{~h}^{-1}$.

É importante mencionar que a taxa respiratória e a produção de etileno foram quantificadas diariamente, enquanto os índices de escurecimento e de amaciamento foram determinados em dias alternados.

Os resultados expressos em porcentagem foram transformados em arc-sen $[(\mathrm{x}+0,5) / 100]^{-1 / 2}$ antes de serem submetidos à análise de variância. Após a ANOVA, as variáveis que apresentaram significância pelo teste $F(p<0,05)$ foram comparadas pelo teste de Skott \& Knott $(\mathrm{p}<0,05)$.

\section{RESULTADOS E DISCUSSÃO}

Na Tabela 1, estão apresentados os dados da análise inicial, realizada na ocasião da colheita dos frutos.

Após quatro meses de armazenamento a $-0,5$ ${ }^{\circ} \mathrm{C}$, seguido de seis dias a $20{ }^{\circ} \mathrm{C}$ observou-se que o $\mathrm{pH}$ não foi influenciado pelos tratamentos testados (Figura 1). O tratamento-controle caracterizou-se por elevados teores de acidez e de sólidos solúveis, cujos níveis de acidez se assemelharam aos encontrados nos frutos, nos quais se aplicou AVG na pré-colheita, assim como naqueles em que se associou o AVG na pré-colheita e 1-MCP no pré-armazenamento. Já, em relação aos teores de sólidos solúveis (SS), verificouse que a aplicação isolada ou conjunta de AVG e 1-MCP, independentemente da ocasião (pré ou pósarmazenamento) implicou valores intermediários a baixos de sólidos (Figura 1), comparativamente ao tratamento-controle, indicando que estes produtos reduziram a solubilização dos açúcares.

Segundo Ben-Arie (1995), a firmeza da polpa mínima recomendada para o consumo in natura de caquis 'Fuyu' é de 20 N. Com base nesta afirmação pode-se inferir que os frutos expostos ao 1-MCP, antes ou após o armazenamento, tratados ou não com AVG, apresentaram firmeza da polpa aceitável para comercialização, mesmo após serem mantidos por 4 meses a $-0,5^{\circ} \mathrm{C}$, seguido de seis dias a 20
${ }^{\circ} \mathrm{C}$, o que foi diferente do observado nos caquis do tratamento-controle e nos tratados apenas com AVG em pré-colheita (Figura 1). Verificou-se também que a época de aplicação do 1-MCP (pré ou pósarmazenamento) não influenciou neste parâmetro. Logo, pode-se dizer que o uso combinado de AVG e 1-MCP mostrou eficiência semelhante à aplicação isolada de 1-MCP para a manutenção da firmeza da polpa dos frutos, indicando que a aplicação de AVG em pré-colheita pode ser dispensada.

Comportamento semelhante ao da firmeza da polpa foi constatado na avaliação do índice de amaciamento nos frutos mantidos a $-0,5{ }^{\circ} \mathrm{C}$ por quatro mais seis dias a $20^{\circ} \mathrm{C}$ (Figura 2). Na saída da câmara e aos dois dias a $20^{\circ} \mathrm{C}$, os frutos de todos os tratamentos apresentavam consistência firme, o que foi coincidente ao encontrado por Brackmann et al. (2006). Já, no $4^{\circ}$ e $6^{\circ}$ dias, praticamente todos os frutos do controle e os tratados apenas com AVG em pré-colheita apresentavam a superfície totalmente amaciada

A rápida perda da consistência de caquis previamente mantidos sob baixas temperaturas e expostos a $20{ }^{\circ} \mathrm{C}$ é consequência da ocorrência de dano pelo frio (WOOLF et al., 1997), que implica desestruturação das paredes celulares e da lamela média e perda de ligação entre as células (PÉREZ-MUNUERA et al., 2009), levando à perda da integridade celular e da função. Com base nos resultados encontrados neste trabalho, pode-se dizer que a aplicação de 1-MCP antes ou após o armazenamento refrigerado, conferiu aos frutos maior resistência a danos pelo frio, a qual refletiu no retardo do amaciamento da polpa dos caquis (SALVADOR et al., 2004; BESADA et al., 2008).

Os frutos de todos os tratamentos apresentaram incremento na respiração até o quarto dia de exposição a $20^{\circ} \mathrm{C}$, decrescendo no quinto e tornando a aumentar no sexto dia (Figura 2). A principal diferença entre os tratamentos foi observada no $4^{\circ}$ dia, em que a aplicação isolada de AVG em pré-colheita ou sua associação, com 1-MCP antes do armazenamento resultou em maior atividade respiratória. Luo (2007) verificou atraso de cerca de 12 dias na ocorrência do pico respiratório em caquis tratados com 1-MCP, o que diferiu do comportamento constatado neste trabalho.

A produção de etileno pelos frutos, após um dia de exposição a $20^{\circ} \mathrm{C}$, foi baixa e praticamente a mesma entre todos os tratamentos (Figura 2). No segundo dia, observou-se pico na produção, independentemente da aplicação do fitorregulador, porém de menor magnitude nos caquis do controle e nos tratados apenas com AVG. Resultados 
semelhantes foram relatados por Orihuel-Iranzo et al. (2010) em caquis 'Rojo Brillante' tratados com 1-MCP, os quais se caracterizaram pela produção de etileno quase três vezes maior que a detectada nos frutos do controle após serem transferidos à condição ambiente. A maior produção de etileno nos frutos tratados com 1-MCP pode ser explicada pela manutenção da integridade das paredes e das membranas (PÉREZ-MUNUERA et al., 2009), uma vez que a polpa dos frutos não expostos ao 1-MCP estava mais amolecida.

De acordo com Dong et al. (2002), o armazenamento prolongado dos frutos sob baixas temperaturas pode reduzir a capacidade dos mesmos de produzir etileno, o que pode estar associado ao desenvolvimento de danos pelo frio. Logo, o uso de 1-MCP pode ter minimizado os sintomas e mantido a integridade dos tecidos. Essa hipótese é reforçada pela atividade da ACC oxidase, enzima precursora do etileno, cuja atividade foi maior nos frutos expostos ao 1-MCP (Figura 3). Larrigaudiere et al. (1997) sugerem que a redução na atividade enzimática está relacionada à alteração nas propriedades das membranas celulares induzidas pelo frio. Outra hipótese sugere que a ação do etileno, associado ao armazenamento em baixa temperatura $\left(-0,5^{\circ} \mathrm{C}\right)$, promove o desbloqueio do amadurecimento dos frutos de caquis 'Fuyu', que é evidenciado quando estes são transferidos à condição ambiente. Isso explica a baixa produção de etileno pelos frutos do tratamento-controle e nos tratados apenas com AVG em pré-colheita, e o rápido amaciamento da polpa dos mesmos com a exposição a $20^{\circ} \mathrm{C}$. Além disso, indica que o 1-MCP retardou o amadurecimento dos frutos, assim como os eventos relacionados com esse processo.

A cor dos frutos foi significativamente afetada pelos tratamentos testados (Figura 3). Observou-se que a aplicação isolada de 1-MCP ou em associação com AVG em pré-colheita promoveu retardo no desenvolvimento da cor vermelha da casca (Hue), o que também foi relatado por Krammes et al. (2005). Comportamento semelhante foi constatado nos parâmetros luminosidade (L) e cromaticidade (Croma), com os caquis submetidos aos tratamentos supracitados, caracterizando-se pelos maiores valores de $\mathrm{L}$ e pelos menores de Croma, o que é indicativo de que os frutos exibiam casca clara e de tonalidade intensa.

$\mathrm{O}$ uso de 1-MCP antes do armazenamento, associado ou não à aplicação de AVG em précolheita, apesar de não ter diferido do tratamento em que se aplicou 1-MCP após o armazenamento no tocante à firmeza de polpa, proporcionou maior índice de escurecimento da epiderme, concordando com Argenta et al. (2009), que afirmaram que este produto retarda o amaciamento dos frutos, mas não impede seu escurecimento (Figura 3).

Apesar das diferenças verificadas, no momento da colheita, entre os frutos tratados ou não com AVG em pré-colheita (Tabela 1), em póscolheita as principais diferenças foram verificadas entre a aplicação ou não de 1-MCP, e entre as épocas em que se realizou esta aplicação do produto.

TABELA 1- Firmeza da Polpa, acidez titulável (AT), sólidos solúveis (SS), pH, atividade respiratória e produção de etileno de caquis 'Fuyu' com e sem a aplicação de AVG (123 $\left.\mathrm{g} \mathrm{ha}^{-1}\right)$, no momento da colheita. Santa Maria, 2011.

\begin{tabular}{|c|c|c|c|c|c|c|}
\hline Condição & $\begin{array}{l}\text { Firmeza } \\
\text { (N) }\end{array}$ & $\begin{array}{c}\text { Acidez } \\
\left(\mathrm{meq} 100 \mathrm{~mL}^{-1}\right)\end{array}$ & $\begin{array}{c}\text { SS } \\
\left({ }^{\circ} \text { Brix }\right)\end{array}$ & pH & $\begin{array}{c}\text { Respiração } \\
\left(\mathrm{mL} \mathrm{CO}_{2} \mathrm{~kg}^{-1} \mathrm{~h}^{-1}\right)\end{array}$ & $\begin{array}{c}\text { Etileno } \\
\left(\mu \mathrm{L} \mathrm{C}_{2} \mathbf{H}_{4} \mathrm{~kg}^{-1} \mathbf{h}^{-1}\right)\end{array}$ \\
\hline Com AVG & 67,1 & 0,73 & 16,93 & 5,84 & 6,73 & 0,0183 \\
\hline Sem AVG & 63,7 & 0,93 & 16,63 & 5,92 & 7,17 & 0,0233 \\
\hline
\end{tabular}



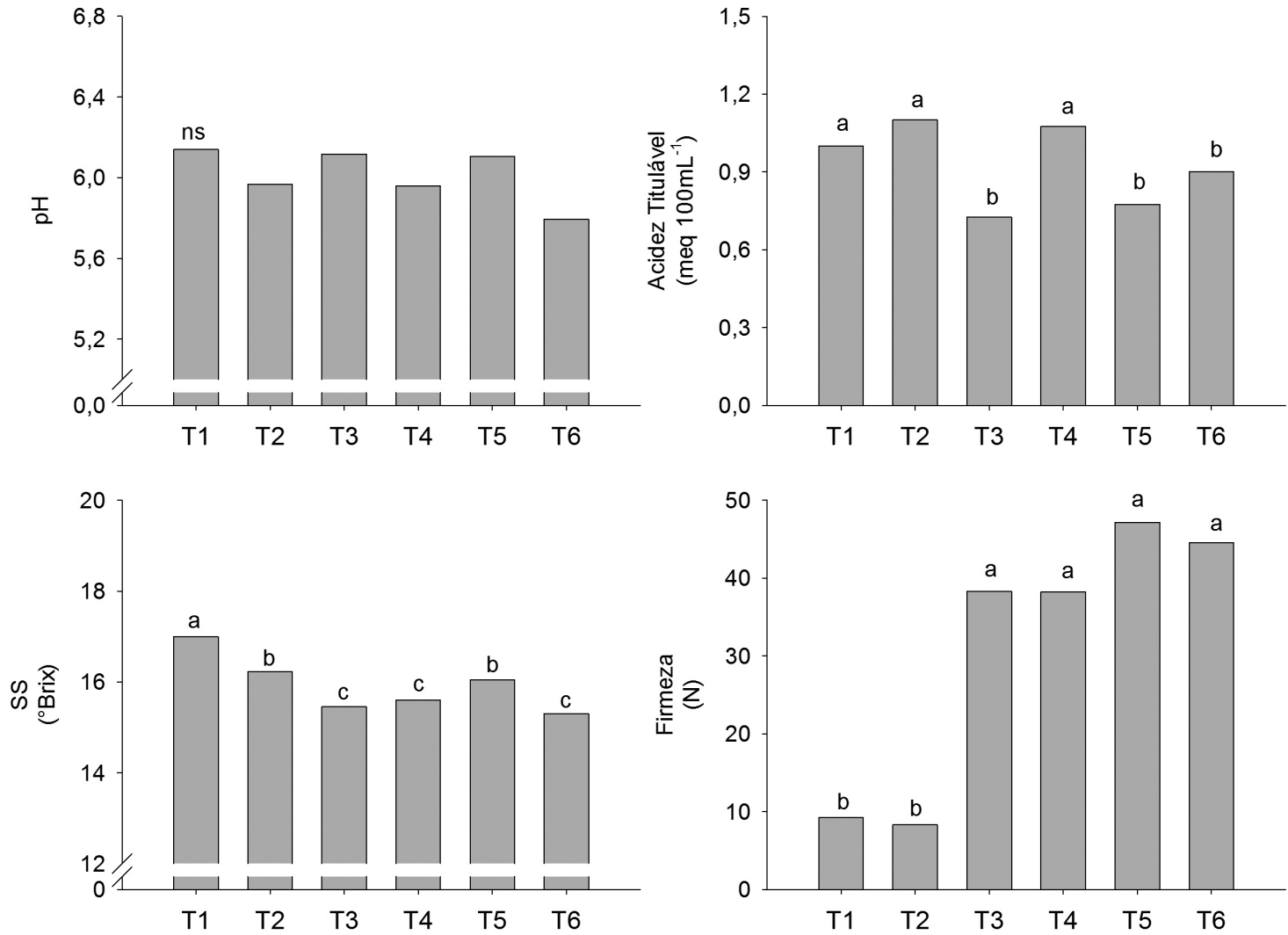

T1: controle; T2: AVG pré-colheita; T3: 1-MCP antes do armazenamento;

T4: AVG pré-colheita + 1-MCP antes do armazenamento; T5: 1-MCP após o armazenamento; T6: AVG pré-colheita + 1-MCP após o armazenamento

FIGURA 1- Efeito dos fitorreguladores AVG e 1-MCP sobre o pH, a acidez titulável, conteúdo de sólidos solúveis (SS) e firmeza de polpa de caquis 'Fuyu' após quatro meses de armazenamento a $-0,5^{\circ} \mathrm{C}$, seguido de seis dias a $20^{\circ} \mathrm{C}$. Santa Maria, 2011. Significância pelo teste SkottKnott, ao nível de $5 \%$ de probabilidade. ns = não significativo a $5 \%$ de probabilidade de erro. 

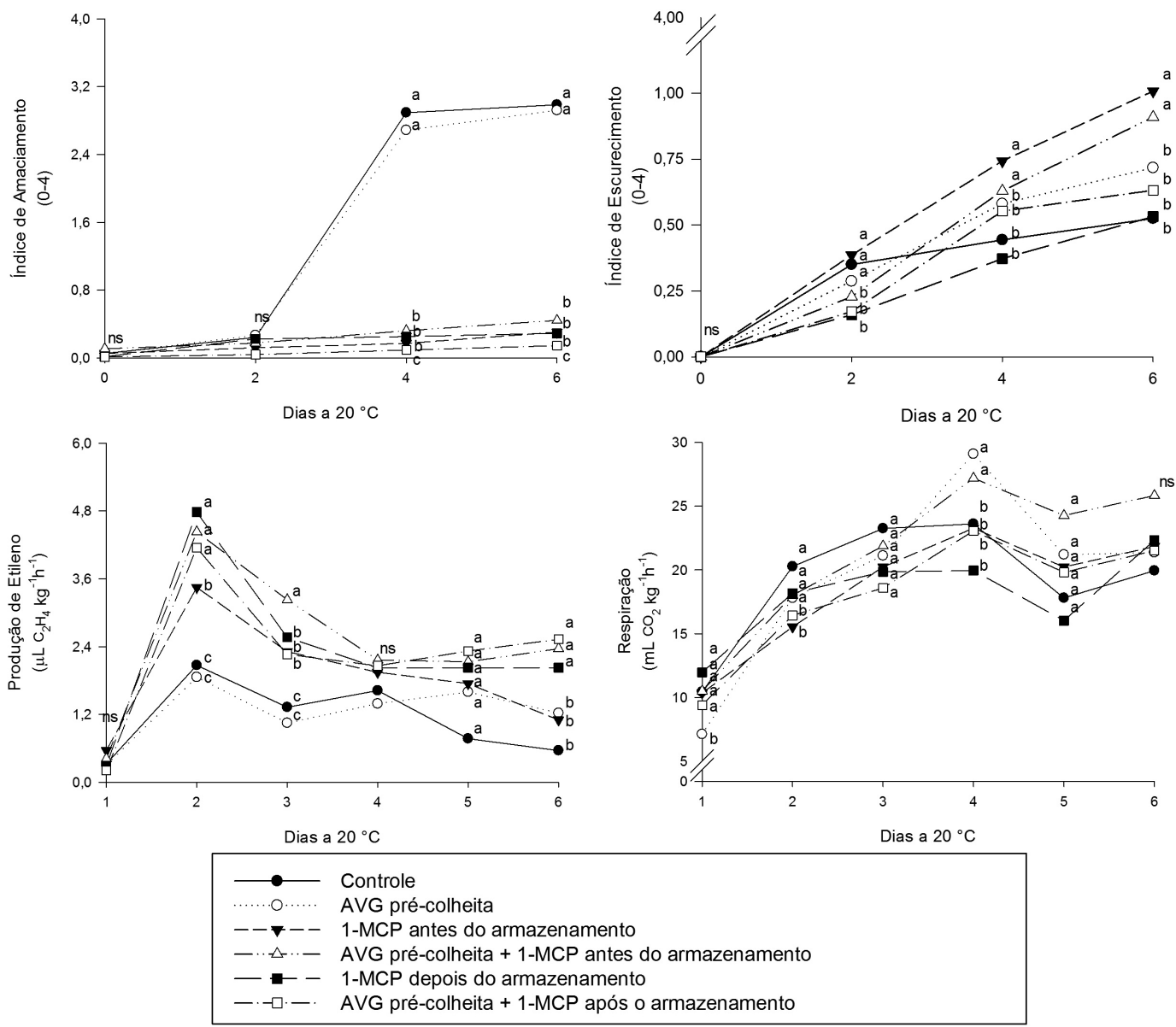

FIGURA 2- Índices de amaciamento e escurecimento, produção de etileno e respiração de caquis 'Fuyu' após quatro meses de armazenamento a $-0,5{ }^{\circ} \mathrm{C}$, seguido de seis dias a $20^{\circ} \mathrm{C}$. Santa Maria, 2011. Significância pelo teste Skott-Knott, ao nível de $5 \%$ de probabilidade. ns = não significativo a $5 \%$ de probabilidade de erro. 

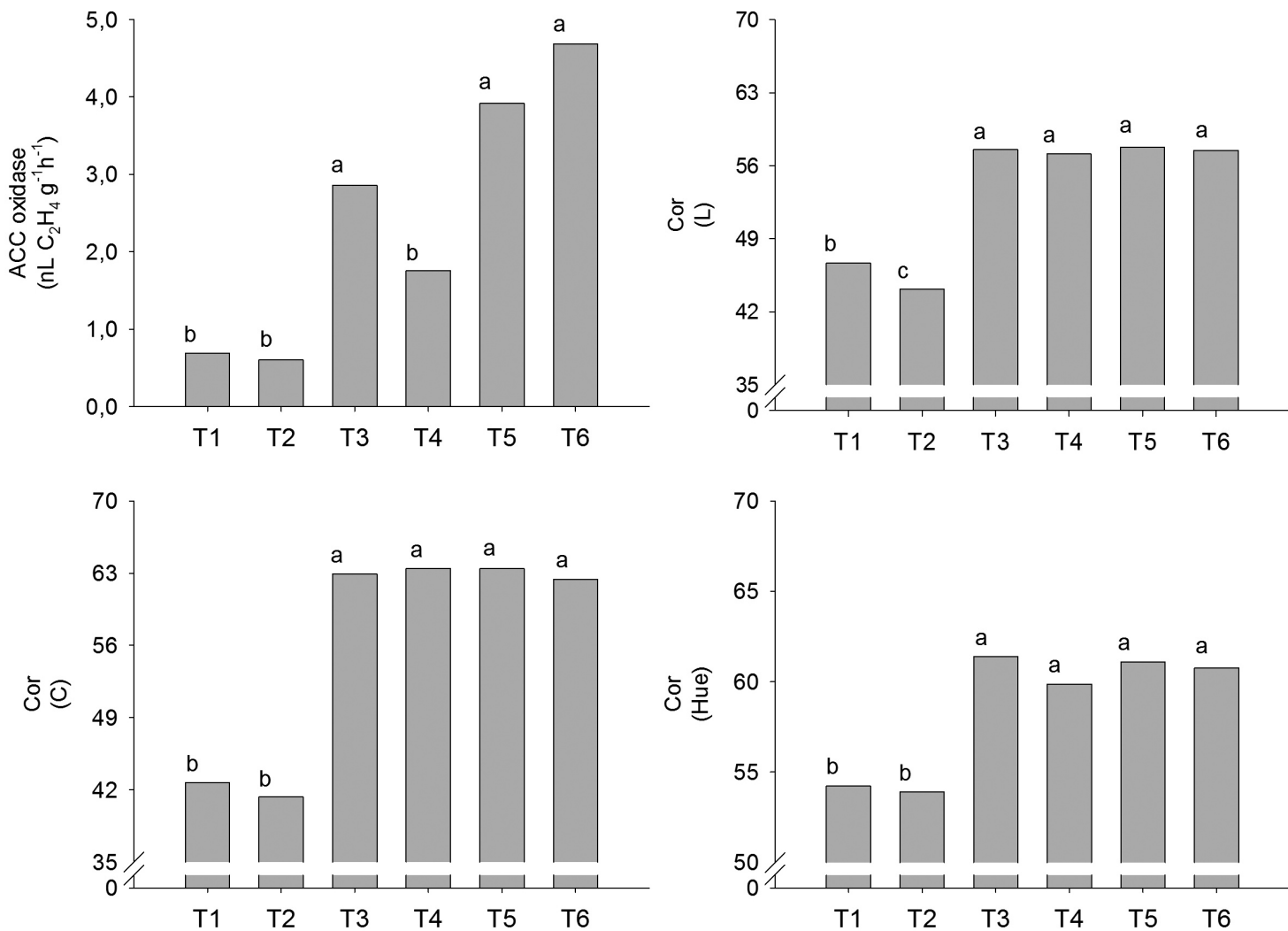

T1: controle; T2: AVG pré-colheita; T3: 1-MCP antes do armazenamento;

T4: AVG pré-colheita + 1-MCP antes do armazenamento; T5: 1-MCP após o armazenamento; T6: AVG pré-colheita + 1-MCP após o armazenamento

FIGURA 3- Atividade da enzima ACC oxidase e cor (Luminosidade, Croma e Hue) de caquis 'Fuyu' após quatro meses de armazenamento a $-0,5{ }^{\circ} \mathrm{C}$, seguido de seis dias a $20^{\circ} \mathrm{C}$. Santa Maria, 2011. Significância pelo teste Skott-Knott, ao nível de 5\% de probabilidade.

\section{CONCLUSÃO}

1-A aplicação de 1-MCP em pré ou em pós-armazenamento foi eficiente em conter o amaciamento da polpa de caquis 'Fuyu' previamente armazenados em atmosfera controlada a $-0,5^{\circ} \mathrm{C}$ e mantidos a $20^{\circ} \mathrm{C}$ por seis dias. Todavia, o uso deste fitorregulador em pré-armazenamento ocasionou maior escurecimento da epiderme.

2- O uso de AVG em pré-colheita não retardou a maturação de caquis 'Fuyu' armazenados na mesma condição.

\section{REFERÊNCIAS}

ARGENTA, L.C.; VIEIRA, M.J.; SCOLARO, A.M.T. Conservação da qualidade de caqui 'Fuyu' em ambiente refrigerado pela combinação de 1-MCP e atmosfera modificada. Revista Brasileira de Fruticultura, Jaboticabal, v.31, n.2, p.323-333, 2009.

BEN-ARIE, R. Commercial quality of 'Fuyu' persimmon. Posthavest Biology and Technology, Amsterdam, v.14, n.3, p.311-317, 1995. 
BESADA, C.; ARNAL, L.; SALVADOR, A. Improving storability of persimmon cv. Rojo Brillante by combined use of pre-harvest and postharvest treatments. Postharvest Biology Technology, Amsterdam, v.50, n.2-3, p.169-175, 2008.

BRACKMANN, A.; PINTO, J.A.V.; NEUWALD, D.A.; GIEHL, R.F.H.; SESTARI, I. Temperaturas para o armazenamento de caquis 'Fuyu'. Revista da FZVA, Uruguaiana, v.13, n.1, p.82-89, 2006.

COLLINS, R.J.; TISDELL, J.S. The influence of storage time and temperature on chilling injury in Fuyu and Suruga persimmon (Diospyros kaki L.) grown in subtropical Australia. Postharvest Biology and Technology, Amsterdam, v.6, n.1-2, p.149-157, 1995.

DONG, L.; LURIE, S.; ZHOU, H. Effect of 1-methylcyclopropene on ripening of 'Conino' apricots and 'Royal Zee' plums. Postharvest Biology and Technology, Amsterdam, v.24, n.2, p.135-145, 2002.

FERRI, V. C.; RINALDI, M.M.; DANIELI, R.; LUCHETTA, L.; ROMBALDI, C.V. Controle da maturação de caquis 'Fuyu', com o uso de aminoethoxivinilglicina e ácido giberélico. Revista Brasileira de Fruticultura, Jaboticabal, v.24, n.2, p.344-347, 2002.

IBGE. Produção agrícola municipal 2011. Rio de Janeiro: IBGE, 2012. Disponível em: em: $<\underline{\mathrm{http}} / / /$ www.ibge.gov.br/estadosat/temas.php?sigla=rs\&te

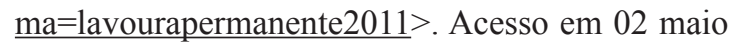
2013.

KRAMMES, J.G.; ARGENTA, L.C.; VIEIRA, M.J. Controle da maturação e conservação da qualidade pós-colheita de caqui 'Fuyu' pelo manejo do etileno. Revista Brasileira de Fruticultura, Jaboticabal, v.27, n.3, p.360-365, 2005.

LARRIGAUDIERE, C.; GRAELL, J.; SALAS, J.; VENDRELL, M. Cultivar differences in the influence of a short period of cold storage on ethylene biosynthesis in apples. Postharvest Biology Technology, Amsterdam, v.10, n.1, p.21-27, 1997.
LUO, Z. Effect of 1-methylcyclopropene on ripening of postharvest persimmon (Diospyros kaki L.) fruit. LWT - Food Science and Technology, Zurich, v.40, n.2, p.285-291, 2007.

ORIHUEL-IRANZO，B.; MIRANDA，M.; ZACARÍAS, L.; LAFUENTE. Temperature and ultra-low oxygen effects and involvement of ethylene in chilling injury of 'Rojo Brillante' persimmon fruit. Food Science and Technology International, Los Angeles, v.16, n.2, p.159-167, 2010.

PINTO, J.A.V. Armazenamento de caqui 'Fuyu' em função da exposição ao frio, atmosfera controlada e 1-MCP. 2009. 79f. Dissertação (Mestrado em Agronomia) -Universidade Federal de Santa Maria, Santa Maria, 2009.

PÉREZ-MUNUERA, I.; HERNANDO, I.; LARREA, V.; BESADA, B.; ARNAL, L.; SALVADOR, A. Microstructural study of chilling injury alleviation by 1-methylcyclopropene in persimmon. HortScience, Alexandria, v.44, n.3, p.742-745, 2009.

SALVADOR, A., ARNAL, L., MONTERDE, A., CUQUERELLA, J. Reduction of chilling-injury symptoms in persimmon cv. Rojo Brillante by 1-MCP. Postharvest Biology and Technology, Amsterdam, v.33, n.3, p.285-291, 2004.

SISLER, E.C. Ethylene binding components in plants. In: MATTOO, A.K.; SUTTLE, J.C. (Ed.). The plant hormone ethylene. Boca Raton: CRC Press, 1991. p.81-99.

WOOLF, A.B.; BALL, S.; SPOONER, K.J. Reduction of chilling injury in the sweet persimmons 'Fuyu' during storage by dry air heat treatments. Postharvest Biology and Technology, Amsterdam, v.11, n.3, p.155-164, 1997.

YANG, S.F.; HOFFMANN, N.E. Ethylene biosynthesis and its regulation in higher plants. Annual Review of Plant Physiology, Palo Alto, v.35, p.155-189, 1984. 